\title{
Increasing Use of Hair Dye and Associated Genotoxicity Needs to be Probed
}

\author{
Safia Habib ${ }^{1}$ - Asif Ali ${ }^{1}$
}

Published online: 13 January 2020

(C) Association of Clinical Biochemists of India 2020

Over the past several decades, societies had been influenced by the ability to maintain and enhance youth. Use of henna (Lawsonia inermis) is known to be the part of human culture; being a natural form of hair dye it usually does not pose any health issues. Still there are reports of type I allergy in hair dressers as occupational hazards [1]. This could be mainly due to its active ingredient Lawsone (2hydroxy-1, 4-napthoquinone). Now henna is being replaced by synthetic hair dye formulations. These formulations are classified according to their ability to penetrate the hair shaft. In order to achieve this $\mathrm{pH}$, the medium has to be maintained towards alkaline side by adding ammonia to it. Products which are tagged to be ammonia free contain ethanolamine to open up the scales and allow the pigment to enter.

Cosmetic industry has flourished and involves multimillion dollars. They are associated with frequent use of both plant derived and synthetic aromatic amines as formulations for preparing hair dyes. Although FDA requires a warning stating that "The following product may contain ingredient(s) allergic to skin and has been determined to cause cancer in laboratory animals". Still obsessed with present ability; we forget these warnings [2].

Usually, in market we have a choice of temporary (azo derivatives and indoamines), semipermanent (nitroamines and anthroquinones) and permanent (para and orthophenylene diamines) hair dyes. All the mentioned ingredients had been banned. The formulations now contain compounds that are derivatives of these, posing similar toxicity

Asif Ali

asifali_amu@rediffmail.com

1 Department of Biochemistry, J. N. Medical College, AMU, Aligarh 202002, India issues. The hair shaft has three major components- cuticle, cortex and the medulla. Temporary hair dye does not penetrate the cortex whereas permanent hair dyes penetrate deeper and gets deposited in the cortex [3].

Epidemiological data has indicated growing incidence of cancers associated with occupational exposure to hair dyeing ingredients. In 2008 an estimated 69,000 new bladder cancer cases associated with exposure to aromatic amines were reported within United States. Reports also correlate maternal hair dye use with increasing risk of neuroblastoma, brain tumours, germ cell tumour in off springs [4, 5]. In 2010 Preston et al. reported that the data is not enough to support these findings that hair dye may increase risk of cancers in individuals exposed to such formulations, either occupationally or personally.

The other side of the story is that the chemical components present in these formulations are known to be mutagenic and carcinogenic in nature. Further, there are reports that clearly indicate the role of different kinds of free radicals participating in site directed DNA damage induced by phenylene diamine and its derivatives [6]. Nohynek et al. reported that preferential DNA damage and poor repair determine mutational hotspot in cancers. Some supporting reports say that reactive oxygen species may induce double base lesions, which our system cannot detect and hence escape, progressing to cancers [7].

Identifying cytogenic alterations and DNA damage in persons exposed occupationally or personally with hair dyes must be explored, as we know that exposure through scalp is greater than through hands. Also the occupational subgroups need to be formed according to the work assigned. We also need to have study specific control groups, better study size and methodology to come to the conclusion about the genotoxicity being associated or not with hair dye exposures. 


\section{References}

1. Gavazzoni Dias MFR. Hair cosmetics: an overview. Int J Trichol. 2015;7:2-15.

2. Nohynek GJ, Fautz R, Benech-Kieffer F, Toutain H. Toxicity and human health risk of hair dyes. Food Chem Toxicol. 2004;42:517-43.

3. Silva JD. DNA damage induced by occupational and environmental exposure to miscellaneous chemicals. Mutat Res. 2016;770:170-82.

4. Zhang Y, Holford TR, Leaderer B, Boyle P, Zahm SH, Flynn S, Tallini G, Owens PH, Zheng T. Hair-coloring product use and risk of non-Hodgkin's lymphoma: a population-based case-control study in Connecticut. Am J Epidemiol. 2004;159:148-54.
5. Correa A, Mohan A, Jackson L, Perry H, Helzlsouer K. Use of hair dyes, hematopoietic neoplasms, and lymphomas: a literature review. I. Leukemias and myelodysplastic syndromes. Cancer Investig. 2000;18:366-80.

6. Preston JR, Skare JA, Aardema MJ. A review of biomonitoring studies measuring genotoxicity in humans exposed to hair dyes. Mutagen. 2010;25:17-23.

7. Murata M, Nishimura T, Chen F, Kawanishi S. Oxidative DNA damage induced by hair dye components ortho-phenylenediamines and the enhancement by superoxide dismutase. Mutat Res. 2006;607:184-91.

Publisher's Note Springer Nature remains neutral with regard to jurisdictional claims in published maps and institutional affiliations. 